\title{
ANALISIS SIFAT MEKANIK BAJA SKD 61 DENGAN BAJA ST 41 DILAKUKAN HARDENING DENGAN VARIASI TEMPERATUR
}

\author{
Media Nofri ${ }^{1}$, Acang Taryana ${ }^{2}$ \\ Program Studi Teknik Mesin, Institut Sains dan Teknologi Nasional, Jakarta Selatan ${ }^{1} 2$ \\ email ${ }^{1}$ : medi.bagindo@gmail.com
}

\begin{abstract}
The alloy steel that is widely used in the world of manufacturing industry is the type of tool steel because it has special characteristics and includes special steel. One type of tool steel that is widely used by the manufacturing industry is SKD steel type 61. ST 41 steel material is a low carbon steel with a carbon content of $0.08 \%-0.20 \%$. ST 41 steel is commonly used as industrial machine component, but in this ST 41 steel is not as strong as steel SKD 61. So, to improve quality to ST 41 steel. Quality improvement can be done by heat treatment process. To obtain hardness requires the heating process, holding time, cooling medium, precise hardening temperature and see the material comparison between SKD 61 steel and ST 41 steel before and after the hardening process to the nature of hardness and microstructure. Result of hardness test of SKD 61 nonheattreatment steel material has hardness value equal to $197 \mathrm{HV}$, ST 41 nonheatreatment steel material has hardness value equal to $165 \mathrm{HV}$, after hardening for temperature $900^{\circ} \mathrm{C}$ has hardness value $154 \mathrm{HV}$, temperature $950^{\circ} \mathrm{C}$ has hardness value $152 \mathrm{HV}$, temperature $1000^{\circ} \mathrm{C}$ has $161 \mathrm{HV}$ magnification value. Seen in the metallographic results appear to be a change in microstructure on ST 41 steel which after the hardening structure looks more dominant after the hardening structure turned into bainite-ferrit
\end{abstract}

Keywords: hardening, SKD 61 and ST 41.

\section{PENDAHULUAN}

Baja merupakan material yang banyak digunakan dalam kegiatan sektor perindustrian. Pada kondisi operasi atau penggunaannya, baja telah diketahui memiliki sifat mekanik tertentu seperti kekerasan. Sifat mekanik tersebut dapat diperbaiki dengan melakukan beberapa proses perlakuan salah satunya yaitu perlakuan mekanik atau perlakuan panas.

Baja perkakas mempunyai kakrakteristik khusus antara lain tahan terhadap abrasi tahan terhadap beban kejut, tahan terhadap temperatur tinggi, tahan terhadap distorsi dan mempunyai kemampuan memotong yang tinggi. Karena baja perkakas juga termasuk ke dalam kelompok baja karbon tinggi, baja perkakas di Indonesia hampir seluruhnya masih impor. Salah satu jenis perkakas yang banyak dipakai oleh industri manufaktur adalah jenis baja SKD 61 untuk aplikasi pada die casting, ekstrusi, press, forging dies, dan lain-lain

Baja ST 41 merupakan salah satu dari golongan baja karbon rendah dimana baja ini memiliki kombinasi sifat mekanik yang baik seperti : kekerasan, keuletan, dan ketangguhan yang baik. Baja karbon rendah sering digunakan untuk bagian-bagian mesin seperti: gear, rantai, skrup dan poros, dan lain-lain.

Perlakuan panas (heat treatment) adalah memanaskan logam pada suhu tertentu dengan kecepatan pemanasan tertentu kemudian didiamkan dalam jangka waktu tertentu dan didinginkan kembali dengan perubahaan kecepatan pendinginan tertentu dengan media udara atau cair, seperti oli dan air, sehingga menghasilkan sifat - sifat tertentu yang diinginkan.

Tujuan penelitian ini untuk dapat mengetahui perubahan sifat mekanik dan struktur mikro dengan cara melakukan peningkatan kualitas terhadap material Baja ST 41 dengan menganalisa perubahan sifat material tersebut dengan melakukan metode Hardening kemudian dengan perubahan variasi temperatur untuk mendapatkan perubahan sifat mekanik dan juga struktur mikro.

\section{TINJAUAN PUSTAKA \\ Pengertian Baja}

Baja adalah salah satu logam ferro yang banyak digunakan dalam dunia teknik dan industri. Kandungan baja yang utama diantaranya yaitu besi dan karbon. Kandungan besi (Fe) pada baja sekitar 
97\% dan karbon (C) sekitar 0,2\% hingga 2,1\% sesuai grade-nya. Selain unsur besi (Fe) dan karbon (C), baja mengandung unsur lain seperti mangan (Mn) dengan kadar maksimal 1,65\%, silikon (Si) dengan kadar maksimal $0,6 \%$, tembaga $(\mathrm{Cu})$ dengan kadar maksimal $0,6 \%$, sulfur (S), fosfor (P) dan lainnya dengan jumlah yang dibatasi dan berbedabeda.

Sifat dan produksi baja tersebut banyak dipengaruhi oleh sifat kimia dan proses pembuatannya. Untuk keperluan industri baja dibagi menjadi beberapa kelompok berdasarkan beberapa karakteristik umum. Baja merupakan paduan yang terdiri dari besi, karbon dan unsur paduan lainnya. Baja dapat dibentuk melalui pengecoran, pencanaian, atau penempaan unsur karbon dalam baja merupakan salah satu unsur terpenting karena dapat meningkatkan kekerasan dan keuletan baja tersebut, sebagai bahan produk, baja sering dijumpai dalam bentuk plat, batang, profil, dan sebagainya

Klasifikasi Baja Karbon terdiri baja karbon rendah (Low Carbon Steel), baja karbon sedang (Medium Carbon Steel) dan baja karbon tinggi (High Carbon Steel). Baja Paduan terdiri dari Baja paduan rendah (Low Alloy Steel), Baja paduan menengah (Medium Alloy Steel) dan Baja paduan tinggi (High Alloy Steel).

\section{Diagram Fasa Fe-C}

Fasa didefinisikan sebagai bagian dari bahan yang memiliki struktur atau komposisi tersendiri. Diagram fasa $\mathrm{Fe}-\mathrm{C}$ atau biasa disebut diagram kesetimbangan besi karbon merupakan diagram yang menjadi parameter untuk mengetahui segala jenis fasa yang terjadi di dalam baja dengan segala perlakuannya. Konsep dasar dari diagram fasa adalah mempelajari bagaimana hubungan antara besi dan paduannya dalam keadaan setimbang. Hubungan ini dinyatakan dalam suhu dan komposisi, setiap perubahan komposisi dan perubahan suhu akan mempengaruhi struktur mikro. Pada diagram fasa Fe-C yang ditampilkan muncul larutan padat $(\alpha$, $\gamma, \delta)$ atau disebut besi delta $(\delta)$, austenit $(\gamma)$ dan ferit $(\alpha)$. Ferit mempunyai struktur Kristal BCC (Body Centered Cubic) dan austenit mempunyai struktur kristal FCC (Face Centered Cubic) sedangkan besi delta $(\delta)$ mempunyai struktur kristal FCC pada suhu tinggi. Apabila kandungan karbon melebihi batas daya larut, maka akan membentuk fasa kedua yang disebut karbida besi atau sementit. Karbida besi mempunyai komposisi kimia Fe3C yang sifatnya keras dan getas. Peningkatan kadar karbon pada baja akan meningkatkan sifat mekanik baja tersebut, terutama kekerasan karena sifat yang dimiliki oleh endapan sementit yang keras.

Diagram fasa menunjukan hubungan struktur mikro dengan sifat-sifat mekanis suatu material, yang semuanya berhubungan dengan karakteristik diagram fasanya. seperti terlihat pada gambar 1

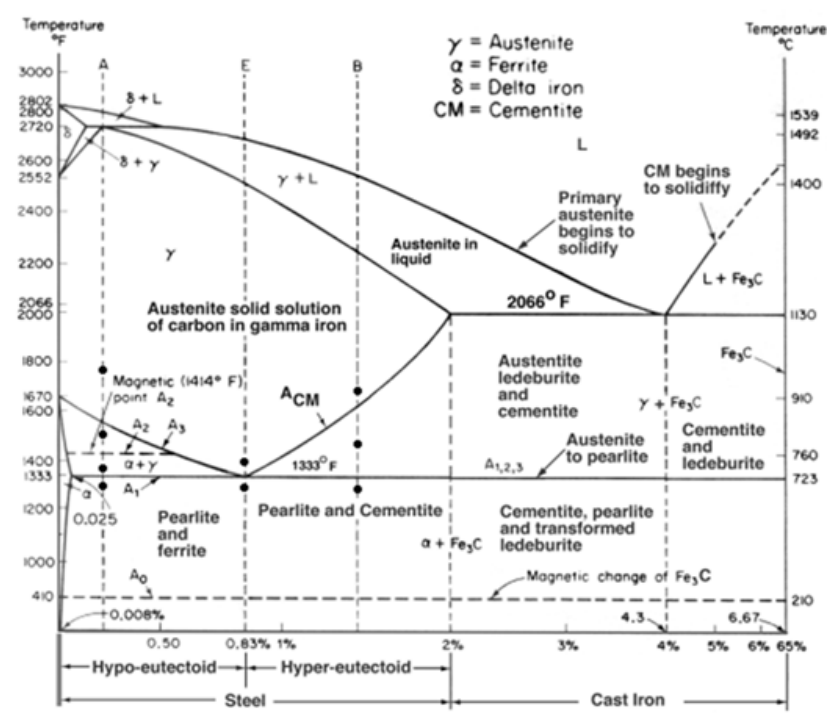

Gambar 1 Diagram Fasa Fe3C

\section{Ferit atau besi Alfa ( $\alpha$ )}

Ferit merupakan suatu larutan padat karbon dalam struktur besi murni yang memiliki struktur BCC dengan sifat lunak dan ulet. Karena ferit memiliki struktur BCC (Body Centered Cubic), maka ruang antar atom-atomnya adalah kecil dan padat sehingga atom karbon yang dapat tertampung hanya sedikit sekali sekitar $0,02 \%$ C. Fasa Ferit mulai terbentuk pada temperatur antara $300^{\circ} \mathrm{C}$ hingga mencapai temperatur $727^{\circ} \mathrm{C}$.

\section{Perlit}

Perlit merupakan campuran antara Ferit dan Sementit yang berbentuk seperti pelat-pelat yang disusun secara bergantian antara Sementit dan Ferit. Fasa Perlit ini terbentuk pada saat kandungan karbon mencapai $0,76 \%$ C, besi pada fase Perlit akan memiliki sifat keras, ulet dan kuat

\section{Martensit}

Adalah suatu fasa yang terjadi karena pendinginan yang sangat cepat sekali, dan terjadi pada suhu dibawah eutektoid tetapi masih diatas suhu kamar. Karena struktur Austenit FCC tidak stabil maka akan berubah menjadi struktur BCT secara serentak. Pada reaksi ini tidak terjadi difusi tetapi terjadi pengerasan (dislokasi)/ semula atom bergerak serentak dan perubahan ini langsung dengan sangat cepat dimana semua atom yang tinggal tetap berada pada larutan padat karena terperangkap dalam kisi sehingga sukar menjadi slip, maka Martensit akan menjadi kuat dan keras tetapi sifat getas dan rapuh menjadi tinggi. Martensit dapat terjadi bila Austenit didinginkan dengan cepat sekali (dicelup) hingga temperatur dibawah pembentukkan bainit. 


\section{Baja ST 41}

Baja ST 41 adalah salah satu dari baja karbon rendah. Bahan ini termasuk dalam golongan baja karbon rendah karena dalam komposisinya mengandung karbon sebesar 0,08\%-0,20\%. Baja karbon rendah sering digunakan dalam komponen mesin-mesin industri seperti gear, rantai,skrup dan poros. Selain itu juga baja ST 41 juga digunakan sebagai handle rem sepeda motor, bodi mobil, pipa saluran, kontruksi jembatan, rivet. Baja ST 41 juga merupakan baja struktur sifat-sifat yang dimilki oleh baja ST 41 mempunyai kekuatan yang cukup tinggi, mempunyai nilai kekerasan yang cukup, stabilitas dimensi yang baik.

\section{Baja SKD 61}

Baja SKD 61 merupakan paduan kompleks yang mengandung sejumlah besar unsur paduan seperti Karbon (C), Tungsten (W), Molydenum (Mo), Vanadium (V), Mangan (Mn), dan Chrom (Cr). Baja SKD 61 jenis baja paduan tinggi hypoeutektroid, menurut standarisasi JIS (Japanese Industrial for standar) baja paduan ini dihasilkan dari proses Hot Work Tools Steel dan memiliki keunggulan operasi panas tinggi, ketangguhan yang baik, dan ketahanan aus yang baik. Baja SKD 61 ekuivalen dengan AISI H13 menurut AISI (American Industrial For Standard ).

Aplikasi material baja SKD 61 : Alumunium Extrusion Dies, Die Casting Dies, Heavy Duty Compression Toola, Forming punches, Hot Forging Dies, Plastic Mold Dies, Mold Accessories (plunger sleeve, plunger tip)

\section{Perlakuan panas (Heat treatment)}

Secara umum yang dimaksud dengan perlakuan panas atau sering disebut Heat Treatment adalah memanaskan logam pada suhu tertentu dengan kecepatan pemanasan tertentu, kemudian didiamkan dalam jangka waktu tertentu dan didinginkan kembali dengan perubahaan kecepatan pendinginan tertentu dengan media udara atau cair, seperti oli dan air, sehingga menghasilkan sifat-sifat tertentu yang diinginkan.

\section{Pembentukan Martensit}

Martensit terbentuk jika fasa Austenit dengan cepat ke temperatur rendah. Tranformasi dari fasa Austenit ke Ferit terjadi suatu pendinginan yang begitu cepat, maka atom karbon tersebut terperangkap dalam larutan sehinggga membentuk struktur Martensit. Beberapa faktor yang mempengaruhi transformasi Martensit adalah

1. Proses tranformasi terjadi tanpa difusi dan tidak terjadi perubahan komposisi kimia selama proses berlangsung. Volume yang kecil dari Austenit tiba-tiba struktur kritsalnya berubah oleh gerakan gesekan.

2. Proses tranformasi hanya berlangsung selama pendinginan dan proses ini berhenti jika pendinginan dihentikan. Tranformasi ini tergantung pada termperatur dan tidak tergantung pada waktu, sehingga jumlah dari Martensit yang terbentuk mempunyai hubungan yang tidak linier dengan penurunan waktu, temperatur pembentukan awal martensit ditandai Ms dan temperatur akhir pembentukan ditandai Mf. Jika baja ditahan temperaturnnya Ms, tranformasi Martensit akan berhenti dan tidak akan berlangsung lagi, kecuali jika temperaturny diturunkan kembali secara cepat.

Pembentukan dari suatu paduan yang diberikan tidak dapat berubah, dan temperatur pembentukan Martensit dari suatu paduan tidak dapat diturunkan dengan peningkatkan laju pendinginan. struktur austenit FCC tidak stabil maka akan berubah menjadi struktur BCT secara serentak

\section{Pembentukan Ferrit dan Perlit}

Perlit Merupakan campuran khusus yang terjadi atas dua fasa yang terbentuk austenisasi,dengan komposisi eutektoid bertransformasi menjadi ferit dan karbida. Ini dikarenakan ferit dan karbida terbentuk secara bersamaan dan keluarnya saling bercampur. Apabila laju pendinginan dilakukan secara perlahan-lahan maka atom karbon dapat berdifusi lebih lama dan dapat menempuh jarak lebih jauh,sehingga di peroleh bentuk perlit besar. Dan apabila laju pendinginn lebih dipercepat lagi maka difusi akan terbatas pada jarak yang dekat sehingga menghasilkan lapisan tipis lebih banyak.

\section{Pengaruh unsur paduan pada baja}

1. Silikon (Si); (terkandung dalam jumlah kecil didalam semua bahan besi dan dibubuhkan dalam jumlah yang lebih pada jenis-jenis istimewa). Silikon dapat meningkatkan kekuatan, kekerasan, keuletan, ketahanan aus, ketahanan terhadap panas dan karat serta ketahanan terhadap kekerasan. Tetapi menurunkan regangan, kemampuan untuk dapat ditempa dan dilas.

2. Mangan (Mn); dapat meningkatkan kekuatan, kekerasan, kemampuan untuk dapat di tempering menyeluruh, ketahanan aus, penguatan pada pembentukan dingin, tetapi menurunkan kemampuan serpih.

3. Nikel (Ni); meningkatkan keuletan, kekuatan, pengerasan menyuluruh, ketahanan karat, tahanan listrik (kawat pemanas), tetapi menurunkan kecepatan pendinginan regangan panas.

4. Krom (Cr); meningkatkan kekerasan, kekuatan, batas rentang ketahanan aus, kemampuan diperkeras, kemampuan untuk dapat ditemper menyeluruh, ketahanan panas, 
kerak, karat dan asam, pemudahan pemolesan, tetapi menurunkan regangan (dalam tingkat kecil).

5. Molibdenum (Mo); meningkatkan kekuatan tarik, batas rentang, kemampuan untuk dapat di tempering menyeluruh, batas rentang panas, ketahanan panas dan batas kelelahan, suhu pijar pada perlakuan panas, tetapi menurunkan regangan.

6. Kobalt (Co); meningkatkan kekerasan, ketahanan aus, ketahanan karat dan panas, daya hantar listrik serta kejenuhan magnetis

7. Vanadium (V); meningkatkan kekuatan, batas rentang, kekuatan panas dan ketahanan lelah, suhu pijar pada perlakuan panas, tetapi menurunkan kepekaan terhadap sengatan panas yang melewati batas pada perlakuan panas.

8. Wolfram (W); meningkatkan kekerasan, kekuatan, batas rentang, kekuatan panas, ketahanan terhadap normalisasi dan daya serat, tetapi menurunkan regangan.

9. Titanium (Ti); memiliki kekuatan yang sama seperti baja, mempertahankan sifatnya hingga $400^{\circ} \mathrm{C}$, misalnya kawat las.

\section{Uji Kekerasan}

Kekerasan suatu logam merupakan bagian dari sifat mekanis dari suatu logam tersebut. Besarnya nilai kekerasan akan berbeda untuk material yang berbeda pula karena kekerasan material dipengaruhi oleh beberapa faktor seperti struktur material, komposisi material, dan sifat mekanis yang dimiliki oleh material tersebut.

\section{Kekerasan Vickers}

Pengujian dengan metoda Vickers dilakukan dengan penekan oleh intan berbentuk piramida bersudut puncak $136^{\circ}$.

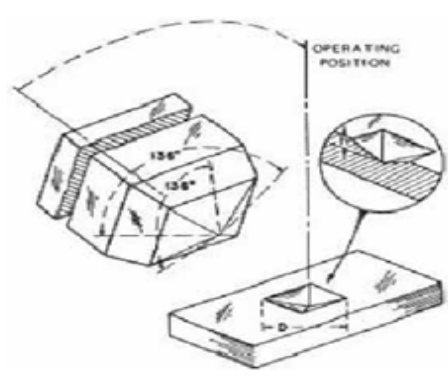

\section{Gambar 2 Indentasi Metode Vickers}

Sudut ini dipilih, karena nilai tersebut mendekati sebagian besar nilai perbandingan yang diinginkan antara diameter bola penekan pada uji kekerasan Vickers. Pada pengukuran kekerasan ini, indentor ditekan ke dalam bahan dengan gaya $\mathrm{F}$ tertentu selama waktu tertentu. Untuk mencari nilai kekerasan Vickers atau VHN (Vickers Hardness

Number) dipakai rumus

$$
V H N=\frac{2 P \cdot \sin \frac{136}{2}}{L^{2}} \text { atau } \quad V H N=\frac{1,854 P}{L^{2}}
$$

\section{Dimana :}

$\mathrm{P}=$ beban penekanan $=1 \mathrm{~s} / \mathrm{d} 120(\mathrm{~kg})$

$\mathrm{L}=$ panjang diagonal rata-rata $(\mathrm{mm})$

$\theta=$ sudut antara permukaan intan yang berlawanan $136^{\circ}$

\section{Pengujian Metallografi}

Pengujian Metalografi dilakukan untuk mengetahui kondisi struktur serta arah perubahan struktur mikro. Berikut ini adalah langkah-langkah proses pengujian Metallografi:

Sampel yang telah disiapkan kemudian dipotong hingga menjadi dua bagian. Kemudian lakukan proses Mounting untuk mempermudah proses Grinding dan Polishising. Kemudian proses pengamplasan dengan menggunakan mesin amplas dan dengan tingkat kekasaran permukaan amplas (nomor urut); 240, 320, 400, 600, 800, 1000, 1200 dan 1500, hingga goresan pada permukaan sampel hilang. Kertas ampelas terbuat dari material Alumunium Oxide Water Proof. Selama proses pengamplasan, dilakukan pendinginan dengan air agar dapat mengurangi akumulasi panas saat pengamplasan dan penghanyutan partikel- partikel garam dan kotoran lainnya. Selanjutnya proses polishising (pemolesan), dengan mesin dan kain poles beludru serta pasta abtasif alumina hingga permukaan sampel bersih dari berbagai macam goresan. Kemudian sampel dibilas dengan larutan alkohol dan dikeringkan. Kemudian proses etsa, yakni sampel dicelupkan \pm selama 5 detik menggunakan larutan Nital sejumlah 2\% (alkohol 95-8 \% dari $100 \mathrm{ml}$ ditambah 2-5\% HNO3). Kemudian keringkan sampel dengan udara hangat untuk meminimalisir terjadinya oksidasi dengan udara di sekitar sampel. Tutup larutan etsa agar tidak terjadi penguapan. Setelah proses peng-etsaan selesai, dilakukan pengamatan (uji struktur mikro) dengan menggunakan mikroskop optik dan dilakukan pemotretan dengan pembesaran 500x dan 1000x.

\section{DIAGRAM ALIR PROSES PENELITIAN}

Dalam melakukan penelitian dibuat diagram alir proses penelitian dengan tahap seperti ditunjukan pada seperti gambar 3 


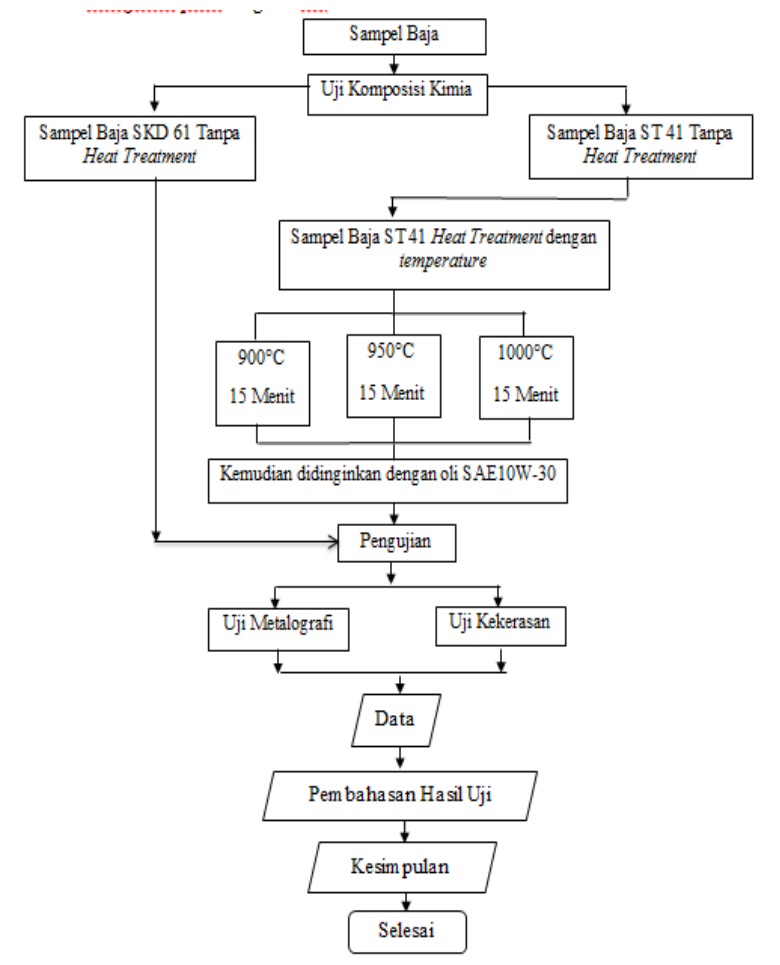

Gambar 3. Diagram Alir Proses Penelitian

\section{PROSES PENELITIAN DAN PEMBAHASAN \\ Persiapan Benda Uji}

Benda uji yang digunakan untuk pengujian dalam penelitian ini adalah baja SKD 61 dan ST 41 dengan diameter $2,5 \mathrm{~cm}$ dan panjang $30 \mathrm{~mm}$ seperti yang terlihat pada gambar 4

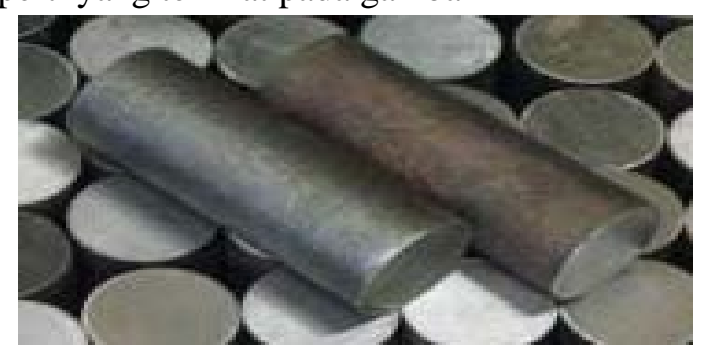

Gambar 4. Sampel benda uji pegas daun

\section{Proses Pemanasan}

Proses pemanasan ini dilakukan dengan metode Hardening dengan temperature yang variasi $900^{\circ} \mathrm{C}-950^{\circ} \mathrm{C}-1000^{\circ} \mathrm{C}$ dengan holding time selama 15 menit, kemudian didinginkan dengan pendinginan media oli SAE10W-30

Berikut adalah proses pemanasan Hardening

1. Setelah dapur induksi panas dan temperatur mencapai $\left(900^{\circ} \mathrm{C} /\right.$ konstan $)$ benda 1 dimasukan kedalam furnance pemanasan selama 15 menit dan langsung dilakukan proses pendinginan yang dicelup dengan oli SAE10W-30.

2. Setelah dapur induksi panas dan temperatus mencapai $\left(950^{\circ} \mathrm{C} /\right.$ konstan $)$ benda 2 dimasukan kedalam furnance pemanasan selama 15 menit dan langsung dilakukan proses pendinginan dengan oil SAE10W-30.

3. Setelah dapur induksi panas dan temperatur mencapai $\left(1000^{\circ} \mathrm{C} /\right.$ konstan $)$ benda 3 dimasukan kedalam furnance pemanasan selama 15 menit dan langsung dilakukan proses pendinginan dengan oli SAE10W-30.

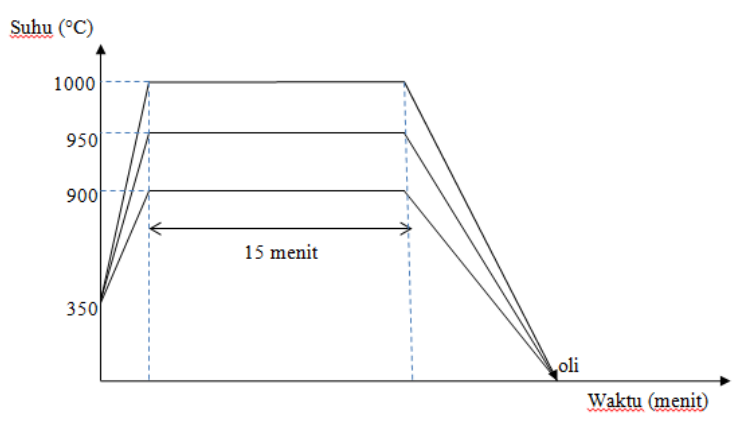

Gambar 5. Diagram pemanasan.pemanasan $900^{\circ} \mathrm{C}-950^{\circ} \mathrm{C}-1000^{\circ} \mathrm{C}$ waktu penahanan 15 menit dengan media pendingin oli

\section{Pengujian Komposisi Kimia}

Pengujian ini bertujuan untuk mengetahui unsur-unsur atau kandungan kimia paduan yang terkandung pada material. Sebelum proses pengujian komposisi kimia dilakukan, sample uji diamplas dan dipoles terlebih dahulu sampai permukaannya rata agar proses pengujian dapat berjalan dengan baik. Proses pengujian komposis kimia dilakukan dengan menggunakan alat spectrometer. Alat uji komposisi kimia dapat dilihat pada gambar berikut ini.

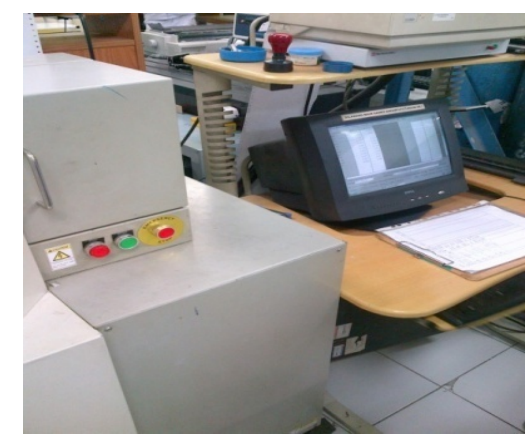

Gambar 6. Instalasi Pengujian Komposisi Kimia.

\section{Persiapan Benda Uji}

Adapun persiapan benda uji yang dilakukan sebagai berikut :

a. Penghalusan permukaan

Untuk benda uji komposisi kimia diusahakan memiliki permukaan yang halus. Alat yang digunakan dalam proses penghalusan ini adalah amplas dengan nomor 400, 600, 800 dan 1000 secara berurutan. 


\section{b. Pemolesan}

Pemolesan benda uji dilakukan dengan menggunakan autosol dan kain halus untuk menghilangkan sisa-sisa goresan dan debu dari hasil pengamplasan agar didapat permukaan yang lebih halus

\section{Hasil Pengujian Komposisi Kimia}

.Tabel 1. Hasil Pengujian Komposisi Kimia Baja SKD 61 dan baja ST 41.

\begin{tabular}{|c|c|c|c|}
\hline Code & No. & Unsure & $\begin{array}{l}\text { Result } \\
\text { (wt } \% \text { ) }\end{array}$ \\
\hline \multirow[t]{14}{*}{ ST 41 } & 1 & $\mathrm{Fe}$ & 99,158 \\
\hline & 2 & C & 0,084 \\
\hline & 3 & $\mathrm{Si}$ & 0,135 \\
\hline & 4 & $\mathrm{Mn}$ & 0,278 \\
\hline & 5 & $P$ & 0,007 \\
\hline & 6 & $\mathrm{~S}$ & 0,0035 \\
\hline & 7 & $\mathrm{Cr}$ & 0,298 \\
\hline & 8 & Mo & 0,008 \\
\hline & 9 & $\mathrm{Ni}$ & 0,005 \\
\hline & 10 & $\mathrm{AI}$ & 0,016 \\
\hline & 11 & $\mathrm{Cu}$ & 0,004 \\
\hline & 12 & $\mathrm{Nb}$ & 0,001 \\
\hline & 13 & $\mathrm{Ti}$ & 0,001 \\
\hline & 14 & V & 0,001 \\
\hline
\end{tabular}

\begin{tabular}{|c|c|c|c|}
\hline Code & No. & Unsure & $\begin{array}{c}\text { Res ul t } \\
\text { (ut \% ) }\end{array}$ \\
\hline SKD 61 & 1 & $\mathrm{Fe}$ & 92,02 \\
\cline { 2 - 4 } & 2 & $\mathrm{C}$ & 0,32 \\
\cline { 2 - 4 } & 3 & $\mathrm{Si}$ & 0,80 \\
\hline & 4 & $\mathrm{Mn}$ & 0,5 \\
\hline & 5 & $\mathrm{P}$ & 0,03 \\
\hline & 6 & $\mathrm{~S}$ & 0,03 \\
\hline 7 & $\mathrm{Cr}$ & 4,50 \\
\hline & 8 & $\mathrm{Mo}$ & 1,00 \\
\hline & $\mathrm{V}$ & 0,80 \\
\hline & & & \\
\hline & & & \\
\hline & & & \\
\hline & & & \\
\hline
\end{tabular}

Berdasarkan data yang diperoleh dari pengujian komposisi kimia yang dilakukan pada material baja SKD 61 dan ST 41 mempunyai komposisi kimia seperti yang ditunjukan pada tabel 1. terlihat bahwa material baja SKD 61 dan ST 41,untuk material baja SKD 61 mempunyai kandungan Fe sebesar 92,02\%, C $0,32 \%$, Si $80 \%$, Cr 4,50\%. Sedangkan untuk material baja ST 41 mempunyai kangdungan $\mathrm{Fe}$ sebesar 99,158\%, C 0,08\%, Si 0,135\%, Mn 0,278\%, Cr 0,298\%.

\section{Pengujian Kekerasan}

Pengujian kekerasan dilakukan dengan menggunakan indektor yang ditekan pada benda uji dengan beban tertentu. Penekanan tersebut akan menyebabkan logam mengalami deformasi plastis. Apabila penekanan diteruskan, deformasi pada benda uji akan terus berlubang. Kemampuan benda uji menahan tekanan indentor inilah yang diartikan sebagai kekerasan material. Beban yang diberikan dalam uji kekerasan adalah konstan. Oleh karena itu nilai kekerasan dari benda uji akan tergantung pada luas permukaan dari benda uji yang mengalami penekanan. Makin luas batas penekanan tersebut, maka makin rendah sifat kekerasan dari benda uji.

Pengujian kekerasan ini dilakukan untuk mengetahui bahan setelah dilakukan proses pemanasan. Nama alat uji yang digunakan untuk uji kekerasan Vickers adalah Frank Finotest dapat dilihat pada gambar 7

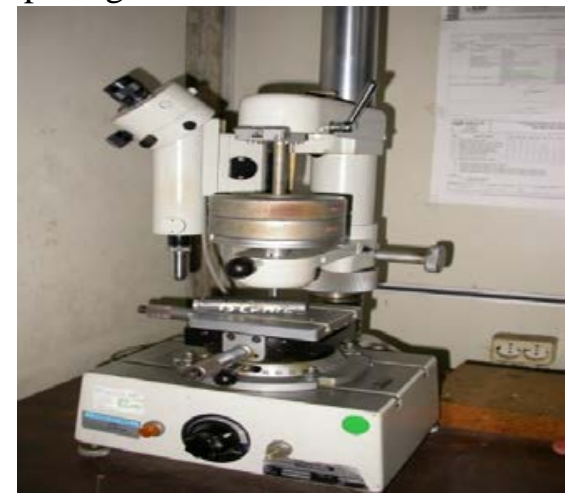

Jambar 7 Alat Uji Kekerasan (Vickers) HV Frank Finotest.

\section{Hasil Pengujian Kekerasan}

Pada pengujian ini menggunakan uji rekerasan jenis Vickers dengan indentor berupa liamond dengan sudut $136^{\circ}$ dan beban $5 \mathrm{kgf}$, emperatur uji $28^{\circ} \mathrm{C}$, dan waktu pengujian 15 detik. 'engujian kekerasan Vickers dilakukan 5 titik pada etiap benda uji kemudian dirata-rata, hasil rata-rata ersebut dapat dilihat pada tabel 2 di bawah ini.

Tabel 2. Hasil uji kekerasan baja SKD 61 dan baja ST 41

\begin{tabular}{|c|c|c|c|c|c|}
\hline \multirow{2}{*}{ N0. } & \multicolumn{5}{|c|}{ NILAI KEKERASAN HV } \\
\cline { 2 - 6 } & SKD 61 & ST 41 & $9000^{\circ} \mathrm{C}$ & $9500^{\circ} \mathrm{C}$ & $1000^{\circ} \mathrm{C}$ \\
\hline 1 & 218 & 171 & 153 & 158 & 158 \\
\hline 2 & 192 & 174 & 147 & 152 & 162 \\
\hline 3 & 194 & 161 & 157 & 149 & 169 \\
\hline 4 & 194 & 163 & 158 & 152 & 157 \\
\hline 5 & 188 & 159 & 156 & 151 & 161 \\
\hline $\begin{array}{c}\text { Rata- } \\
\text { rata }\end{array}$ & 197 & 165 & 154 & 152 & 161 \\
\hline
\end{tabular}

Nilai rata - rata kekerasan pada keseluruhan hasil pengujian hardnes Vickers pada material baja SKD 61 dan baja ST 41, dilakukan proses heat treatment untuk baja ST 41 dengan variasi temperatur dan holding time tetap serta di dinginkan dengan media oli SAE 10W-30. Dapat dilihat nilai rata - rata kekerasan keseluruhan pada baja ST 41. 
Dari hasil uji kekerasan baja SKD 61 dan baja ST 41 bahwa:

1. Baja SKD 61 dengan kode $\mathrm{N}$ (non heat treatment) memiliki nilai rata - rata kekerasan sebesar $192 \mathrm{HV}$.

2. Baja ST 41 dengan kode $N$ (non heat treatment) memiliki nilai rata - rata kekerasan sebesar 165 HV..

3. Baja ST 41 dengan kode 1 yang telah dilakukan proses heat treatment dengan suhu $900^{\circ} \mathrm{C}$ lama pemansan 15 menit dengan media pendinginan oli SAE10W-30 memiliki nilai rata - rata kekerasan sebesar $154 \mathrm{HV}$.

4. Baja ST 41 dengan kode 2 yang telah dilakukan proses heat treatment dengan suhu $950^{\circ} \mathrm{C}$ lama pemansan 15 menit dengan media pendinginan oli SAE10W-30 memiliki nilai rata - rata kekerasan sebesar $152 \mathrm{HV}$.

5. Baja ST 41 dengan kode 3 yang telah dilakukan proses heat treatment dengan suhu $1000^{\circ} \mathrm{C}$ lama pemansan 15 menit dengan media pendinginan oli SAE10W-30 memiliki nilai rata - rata kekerasan sebesar $161 \mathrm{HV}$.

Grafik dibawah adalah nilai rata-rata keseluruhan kekerasan material baja dari pengujian hardnes vickers dapat dilihat pada gambar 8

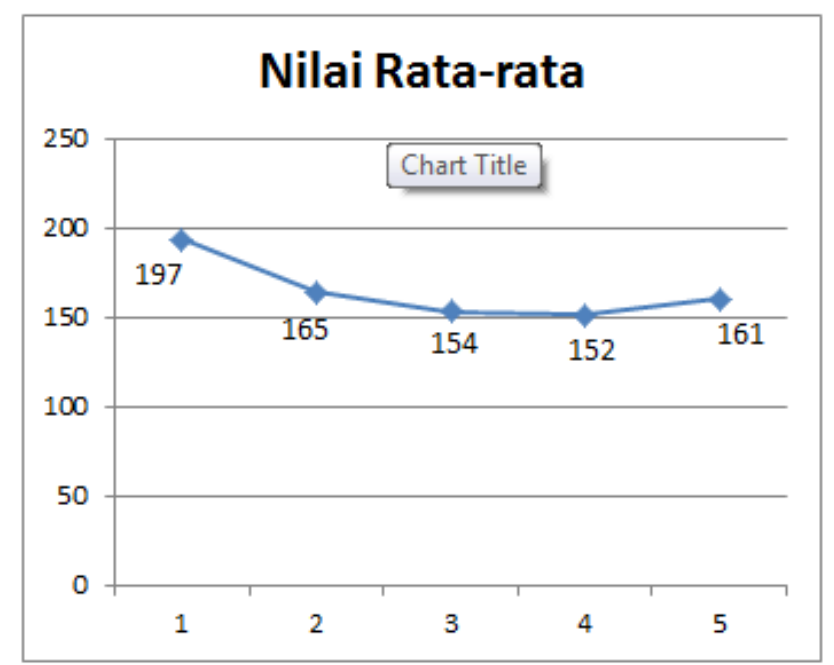

Gambar 8. Nilai rata-rata Uji kekerasan

\section{Pengujian Metalografi (Struktur Mikro)}

Pengujian ini dilakukan untuk mengetahui dan mempelajari bentuk struktur mikro dari logam, termasuk didalammya besar butiran dan arah struktur. Struktur mikro tersebut sangat menentukan sifat mekanis logam yang diuji. Alat uji metalografi terdiri dari beberapa macam alat seperti yang terlihat pada gambar 9 s/d 11 dibawah ini :
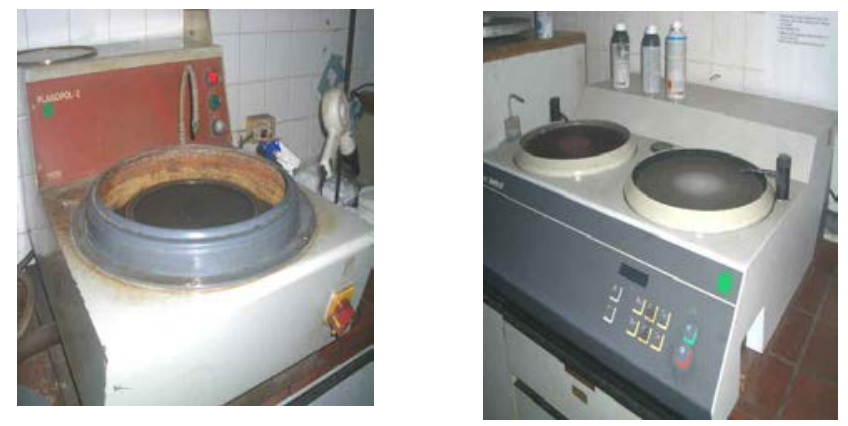

Gambar 9. Mesin grinding Gambar 10. Mesin poles
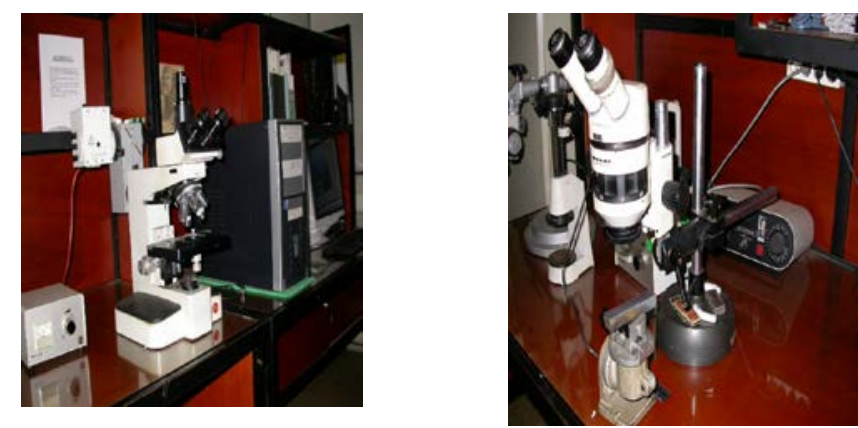

Gambar 11. Mikroskop optik dengan perbesaran 50-1000x (kiri) dan stereo mikroskop makro perbesaran 6-50 x (kanan)

Metode pengujian Metallografi ini memerlukan persiapan yang cukup teliti dan cermat, agar dapat di peroleh hasil pengujian yang baik. Oleh sebab itu diperlukan beberapa tahap dalam persiapannya, yaitu:

1) Pemotongan Benda Uji ( Sampel)

Agar mendapat bentuk struktur benda uji menggunakan mikroskop optik dengan baik, maka benda uji harus dipotong sesuai dengan standar alat uji Metallografi. Pemotongan dilakukan dengan sangat hati-hati agar tidak menimbulkan panas yang berlebihan yang bisa merubah struktur mikro dari benda yang akan diuji.

2) Mounting

Setelah dipotong benda uji kemudian di mounting, yang bertujuan untuk memudahkan pengoperasian selama proses preparasi (grinding dan polishising).

3) Pengamplasan (Grinding )

Pada tingkat pekerjaan ini dipakai mesin grinding putar, atau grinding manual. Sebagai medium grinding berupa kertas ampelas silikon karbit ( $\mathrm{SiC}$ ) dengan berbagai tingkat kekasaran yaitu kombinasi dari 220, 330, 500, 600, 800, dan 1000. Ketika mengrinding diatas kertas ampelas, harus selalu dialiri air bersih secara langsung. Seperti terlihat pada gambar 12. Tujuanya untuk menghindari timbulnya panas dipermukaan benda uji. 


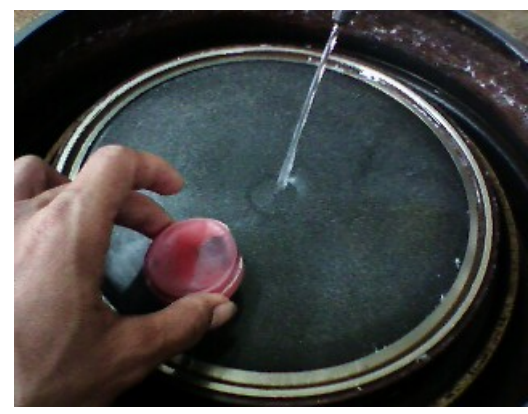

Gambar 12. Proses Grinding

Dalam proses grinding, pertama-tama dikerjakan pada kertas ampelas yang paling kasar misal 220. Hasil preparasi tahap ini diperoleh permukaan dengan goresan - goresan yang searah dan homogen, tidak hanya pada permukaan media cetaknya. Untuk itu dipegang dengan tetap diatas kertas ampelas yang berputar dan diberi sedikit tekanan, agar tidak bergeser ke arah lain. Pengerjaan ketingkat kekerasan selanjutnya misal menggunakan ampelas no 320, dengan di putar $90^{\circ}$ sedemikian sehingga diperoleh goresan baru yang tegak lurus dan relatif lebih halus dari goresan sebelumnya. Demikian seterusnya posisi selalu diubah $90^{\circ}$ pada tingkat kekasaran yang berikutnya.

Hasil akhir dari proses grinding diperoleh permukaan dengan goresan yang searah, halus dan homogen (akibat kekasaran kertas ampelas gradasi 1000 atau 1200). Untuk itu perlu diperiksa dibawah mikroskop optik dengan perbesaran rendah. Sebelumnya perlu dicuci dengan air, alkohol dan dikeringkan dengan alat pengering.

\section{4) Polishising}

Media polishising yang sering dimanfaatkan adalah bentuk pasta, alumunium oksida bentuk suspensi dan sebagainya. Tujuan proses polishising adalah untuk mendapatkan permukaan contoh yang memenuhi syarat untuk diperiksa dibawah mikroskop optik, antara lain:

- Bebas dari goresan akibat proses grinding (sehingga seperti cermin ).

- Bebas dari flek-flek atau cacat lain yang ditimbulkan selama proses grinding.

- Tidak ada perubahan logam, khususnya pada permukaan logam preparat yang akan diselidiki.

Dalam proses polishising, benda uji dipegang kuat, diberi sedikit tekanan dan digerakan berputar setempat berlawanan arah jarum jam. Proses polishising selesai bila goresan - goresan hasil proses grinding tahap terakhir pada permukaanya hilang dan diperoleh permukaan yang seperti cermin.

Selain hal - hal tersebut diatas dalam proses polishising perlu diperhatikan:
- Selama proses berlangsung, media polishising nya tidak boleh terlalu basah atau terlalu kering, untuk menghindari adanya gesekan yang berlebihan.

- Setiap perpindahan ketingkat kekasaran yang lain, harus dicuci dan dikeringkan.

- Waktu polishising tidak terlalu lama, untuk 5) Etsa menghindari timbulnya relief - relief.

Struktur mikro suatu contoh logam dapat dilihat dengan baik melalui mikroskop optik apabila telah mengalami proses etsa dengan medium etsa yang tertentu. Etsa yang dilakukan menggunakan nital $2 \%$ dan dilakukan paling sedikit 3 lokasi pada permukaaan benda uji, dengan variasi waktu yg berbeda-beda pada setiap lokasi.

Pada waktu melakukan pengetsaan harus cepat, tujuannya untuk mempermudah pembersihan permukaan yang telah dietsa dengan air, setelah itu dibersihkan dengan alkohol dan dikeringkan dengan menggunakan udara panas (dryer).

Pada dasarnya adanya perubahan atau perkembangan struktur mikro yang terjadi selama proses etsa, dikarenakan berbagai hal antara lain:

- Perbedaan warna akibat distribusi struktur mikro.

- Jenis kekasaran yang berbeda, akibat perbedaan orientasi kisi - kisi kristalnya.

- Perbedaan kemampuan larut struktur mikro dan sifat anisotrop kristal terhadap agresifitas medium etsa, dapat menimbulkan relief pada perbatasan kristal - kristal.

- Terbentuknya elemen lokal secara elektrokimia pada perbatasan kristal - kristal, sebelum medium etsa bereaksi dengan permukaan kristal tersebut.

Beberapa faktor yang perlu diperhatikan dalam proses etsa, adalah sebagai berikut:

- Kemampuan medium etsa sebagai pereaksi.

- Konsentrasi larutan medium etsa.

- Kemampuan larut logam dalam media etsa.

- Waktu berlangsungnya proses etsa (dalam beberapa detik atau menit, tergantung jenis logam dan reaksitifitas medium etsa nya).

Kesalahan dalam proses etsa akan menyebabkan hal - hal sebagai berikut:

- Timbulnya relief - relief pada permukaan benda uji.

- Terjadi korosi lokal yang homogen.

- Rusaknya struktur mikro yang akan diselidiki.

6) Proses Pencucian

Salah satu kegiatan dalam preparasi yang tidak dapat diabaikan adalah proses pencucian, khususnya antara lain: 
- Proses pencucian setelah proses grinding.

- Proses pencucian setelah proses polishising.

- Proses pencucian setelah mengalami etsa.

Dalam proses pencucian paling sering digunakan air bersih, aquades dan alkohol, baru kemudian dikeringkan dengan alat pengering (contohnya Hair Dryer). Untuk benda uji yang retak atau cacat, maka cara pencucian yang paling baik mencelupkan kedalam peralatan ultrasonic cleaning. Ultrasonic cleaning menggunakan medium cair alkohol atau aceton, dan medium ini bergerak secara ultrasonic oleh karena adanya impuls - impuls listrik.

7) Pengamatan dan Pemotretan

Amati permukaan benda uji yang telah dietsa dengan mikroskop optik pada perbesaran 50x, 100x, 200x dan 500x. pilihlah bentuk struktur paling baik dan jelas untuk selanjutnya dilakukan pemotretan (pengambilan foto) dengan bermacam-macam perbesaran.

\section{Hasil Pengujian Struktur Mikro}

Seperti diketahui bahwa sampel pengujian untuk struktur mikro terdapat lima benda uji dimana benda uji dengan kode $\mathrm{N}$ adalah material baja SKD 61 dan material baja ST 41 tanpa pemanasan, sedangkan benda uji dengan kode 1 adalah baja ST 41 yang sudah mengalami proses pemanasan pada variasi temperatur $900^{\circ} \mathrm{C}$ dengan holding time tetap selama 15 menit dan di dinginkan dengan media pendingin oli SAE10W-30, selanjutnya benda uji dengan kode 2 adalah baja ST 41 yang sudah mengalami proses pemanasan pada variasi temperatur $950^{\circ} \mathrm{C}$ dengan holding time tetap selama 15 menit dan di dinginkan dengan media pendingin oli SAE10W-30, selanjutnya benda uji dengan kode 3 adalah baja ST 41 yang sudah mengalami proses pemanasan pada variasi temperatur $1000^{\circ} \mathrm{C}$ dengan holding time tetap selama 15 menit dan didinginkan dengan media pendingin oli SAE10W-30.

Hasil dari pengujian struktur mikro dengan foto pembesaran 500x pada material baja SKD 61 dan baja ST 41 dengan non heattreatment foto metalografi ditunjukan pada gambar 13 sampai 17
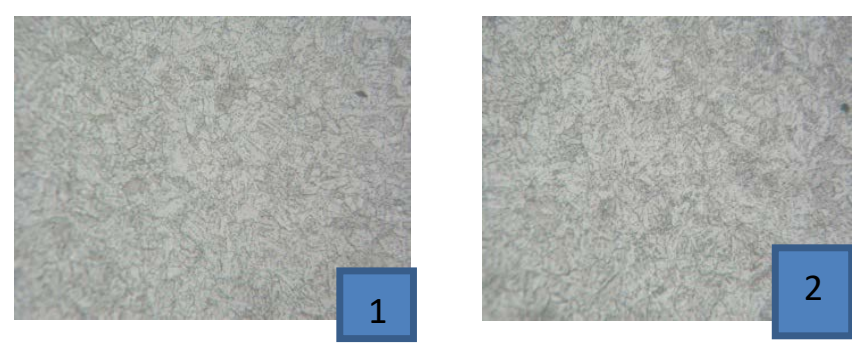

Gambar 13. SKD 61 non heattreatment
Struktur mikro material baja SKD 61 kondisi tanpa perlakuan pada daerah tepi (lokasi 1) berupa matrik Austenite-Bainit dengan butir Karbida Chrome menyebar merata. Etsa: kalling reagent. Struktur mikro material SKD 61 kondisi tanpa perlakuan pada daerah tengah (lokasi 2) berupa matrik Austenite-Bainit dengan butir Karbida Chrome menyebar merata. Etsa: kalling reagent. Dengan nilai rata - rata kekerasan 192 HV.
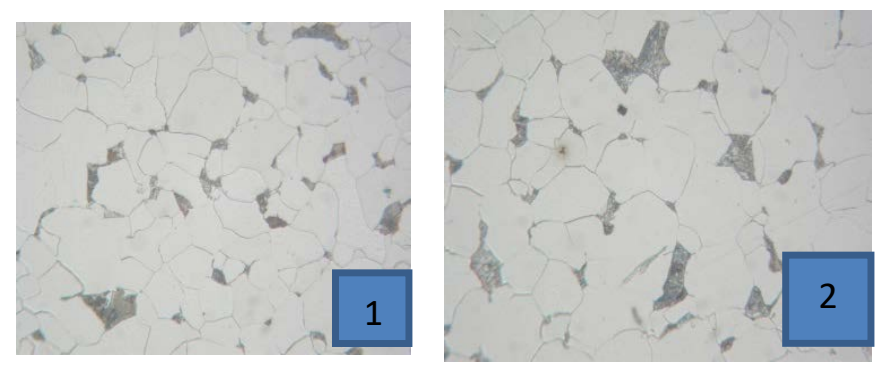

Gambar 14. ST 41 non heattreatment

Struktur mikro material baja ST 41 tanpa perlakuan panas (Lokasi 1) daerah tepi berupa Ferit dan Perlit . Etsa: nital 2\%. Struktur mikro material ST 41 tanpa perlakuan panas. (Lokasi 2) daerah tengah berupa Ferit dan Perlit . Etsa: nital 2\% Dengan nilai rata - rata kekerasan 165 HV.

Hasil dari pengujian struktur mikro dengan foto pembesaran 500x pada material baja ST 41 setelah proses Hardening foto Metalografi ditunjukan pada gambar 15 sampai 17
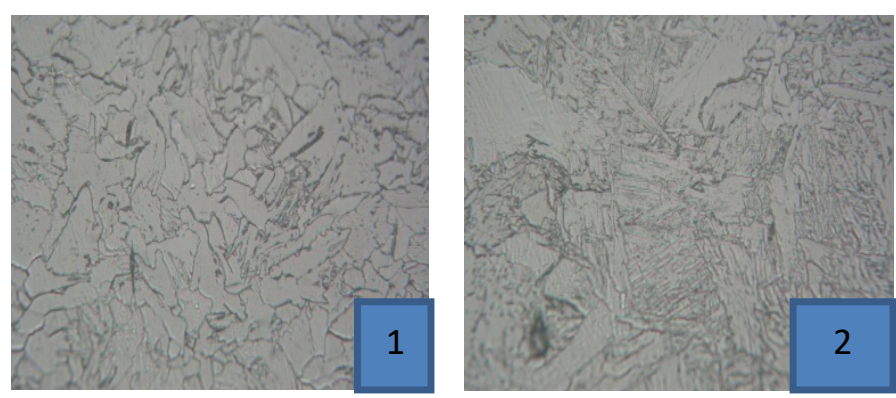

Gambar 15. Baja ST 41 dengan tempertur $900^{\circ} \mathrm{C}$

Pemeriksaan struktur mikro sampel 1 pada lokasi 1 dan 2, sampel perlakuan panas pada temperatur $900^{\circ} \mathrm{C}$ dengan holding time 15 menit dan media pendingin oli. pada daerah satu berupa ferit dan perlit bentuk Bainit-Ferit dengan besar butir tidak merata. Etsa: nital 2\%. Pada daerah dua berupa Ferit dan Perlit bentuk Bainit-Ferit dengan besar butir tidak merata. Etsa: nital 2\%. Dengan nilai rata - rata kekerasan 154 HV. 

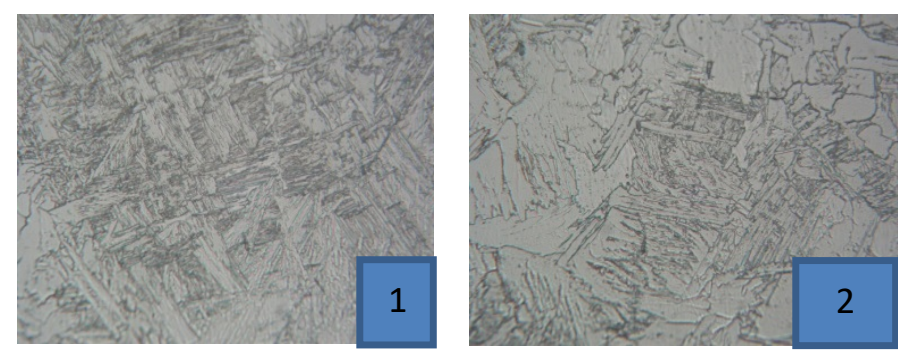

Gambar 16. Baja ST 41 dengan tempertur $950^{\circ} \mathrm{C}$

Pemeriksaan struktur mikro sampel 2 pada lokasi 1 dan 2, sampel perlakuan panas pada temperatur $950^{\circ} \mathrm{C}$ dengn holding time 15 menit dan media pendingin oli. Pada daerah satu berupa Ferit dan Perlit bentuk bainit dengan serpih pelat. Etsa: nital 2\%. Pada daerah dua berupa Ferit dan Perlit bentuk Bainit-Ferit dengan besar butir tidak merata. Etsa: nital 2\%. Dengan nilai rata - rata kekerasan $152 \mathrm{HV}$.
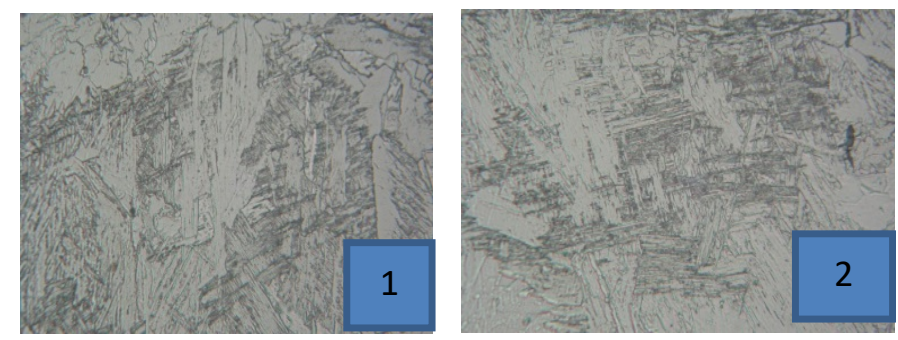

Gambar 17. Baja ST 41 dengan tempertur $1000^{\circ} \mathrm{C}$

Pemeriksaan struktur mikro sampel 3 pada lokasi 1 dan 2 sampel perlakuan panas pada temperatur $1000^{\circ} \mathrm{C}$ dengn holding time 15 menit dan media pendingin oli. pada daerah satu berupa ferit dan perlit bentuk bainit dengan serpih pelat. Etsa: nital 2\%. Pada daerah dua berupa Ferit dan Perlit bentuk Bainit dengan besar butir tidak merata. Terdapat bentuk matrik widmanstatten. Etsa: nital 2\% Dengan nilai rata - rata kekerasan $161 \mathrm{HV}$

\section{SIMPULAN}

Dari hasil penelitian yang telah dilakukan maka dapat diambil kesimpulan sebagai berikut:

1. Hasil uji komposisi kimia dari material baja SKD 61 mempunyai hasil kandung C.0,32\%, dan untuk material baja ST 41 mempunyai kandungan C. 0,08\%,.

2. Hasil pengamatan struktur mikro struktur mikro baja SKD 61 tanpa perlakuan panas berupa autenite-bainit dengan butir Karbida Chrome menyebar merata.

3. Struktrur mikro baja ST 41 tanpa perlakuan panas berupa Ferit dan Perlit setelah di Hardening dengan temperatur $900^{\circ} \mathrm{C}$ berbentuk Bainit-Ferit dengan besar butir tidak merata,

4. Hardening dengan temperatur $950^{\circ} \mathrm{C}$ berupa Ferit dan Perlit bentuk Bainit-Ferit serpih pelat dengan besar butir tidak merata,

5. Hardening dengan temperatur $1000^{\circ} \mathrm{C}$ berupa Bainit serpih plat dengan besar butir tidak merata.

6. Hasil pengujian kekerasan material baja SKD 61 non heattreatment memiliki nilai kekerasan sebesar $197 \mathrm{HV}$,

7. Material baja ST 41 non heatreatment memiliki nilai kekerasan sebesar $165 \mathrm{HV}$, sesudah dilakukan hardening untuk suhu $900^{\circ} \mathrm{C}$ memiliki nilai kekerasan $154 \mathrm{HV}$, suhu $950^{\circ} \mathrm{C}$ memiliki nilai kekerasan 152 $\mathrm{HV}$,suhu $1000^{\circ} \mathrm{C}$ memiliki nilai kekesaran $161 \mathrm{HV}$.

8. Terlihat pada hasil Metalografi tampak perubahan struktur mikro pada baja ST 41 dimana setelah di Hardening struktur terlihat lebih dominan berubah menjadi Bainit-Ferit.

9. Bila dilihat dari uji kekerasan struktur Ferrit adalah lunak sedangkan Bainit keras.

10. Kenyataannya kekerasan baja ST 41 setelah di Hardening strukturnya berubah dibandingkan sebelum di Hardening, namun pada uji kekerasan menurun, hal ini terjadinya adanya kesalahan pada alat yang digunakan.

\section{DAFTAR PUSTAKA}

1. ASM Handbook. 1991. Heat Treating.ASM hanbook Committee. Volume 4. page 17.

2. Adyana D.N, Teknologi Manufaktur Logam Industri, ISTN, Jakarta, 2014.

3. Adi, yeuwono. "Perlakuan Panas Pada Logam Dan Jenisnya”. 04 juni 2011. http://teknosehat.blogspot.co.id/2011/06/PerlakuanPanas-(Heat Treatment)-Pada-Logam-DanJenisnya/

4. Adnyana D.N., Logam dan Paduan Tinjauan Tentang Proses Pengolahan Dan Hubungan Antar Struktur Dengan Sifat Mekanis, Jakarta, 1978.

5. Callister, William D, 2007. Mayerial Science and Engineering7. jhon wiley\&sons,Inc.kanada

6. Suherman, W, Perlakuan Panas, ITS, Surabaya, 1991

7. Adhy Prayitno, Ismet Inonu .Pengaruh Perbedaan Waktu Penahanan Suhu Stabil Terhadap Kekerasan.1999)

8. Djoko Wijono, Teori Praktikum Ilmu Logam, LUK-BPP Teknologi, 1994 
9. Median Fide Susanto (2004), tugas akhir : "PENGARUH PERLAKUAN PANAS TERHADAP SIFAT MEKANIS DAN STRUKTUR MIKRO PADA BAJA KARBON RENDAH $S 30$ C”, Institut Sains dan Teknologi Nasional. Jakarta.

10. .Jhon E.bringas (2004),"Handbook of comparative Word steel standards".

11. Rinto Veni Sinaga (2014), tugas akhir : "PENGARUH NITRIDASI PLASMA TERHADAP PERUBAHAN KEKERASAN, STRUKTUR MIKRO BAJA PERKAKAS SKD61 PLUNGER TIP KOMPONEN MESIN HIGH PRESSURE DIE CASTING". Universitas Mercubuana Jakarta.

12. http://Perlakuan Panas (Heat Treatment) Pada Logam Dan Jenisnya Tekno-Sehat

13. www.google.com 